\title{
A TRADUÇÃO AUTOMÁTICA de TEXTOS CIENTÍFICOS COMO SUPORTE PEDAGÓGICO PARA O DESENVOLVIMENTO DA COMPREENSÃO LEITORA EM INGLÊS PARA PROPÓSITOS ACADÊMICOS
}

\author{
THE AUTOMATIC TRANSLATION OF SCIENTIFIC TEXTS AS A \\ PEDAGOGICAL SUPPORT FOR THE DEVELOPMENT OF READING \\ COMPREHENSION IN ENGLISH FOR ACADEMIC PURPOSES
}

Débora Borsatti ${ }^{1}$, Rosângela Gabriel ${ }^{2}$

\begin{abstract}
RESUMO: Este artigo tem como objetivo apresentar a análise de três tradutores automáticos (TA) disponíveis gratuitamente na internet, buscando problematizar a eficiência dessas ferramentas como suporte para compreensão de textos científicos, tendo em vista as limitações deste tipo de tradução em relação a diferentes elementos linguísticos. O estudo está fundamentado em reflexões sobre leitura e compreensão textual, o conceito de tradução, o funcionamento da tradução através das máquinas, e o uso do tradutor automático como uma estratégia de compreensão leitora em inglês para propósitos acadêmicos. Os resultados apontam diferenças entre os tradutores escolhidos, indicando maior confiabilidade/eficiência de acordo com o sistema empregado, bem como evidenciam a importância da instrumentalização do ensino de estratégias de leitura para garantir a compreensão.
\end{abstract}

PALAVRAS-CHAVE: tradutor automático; leitura; texto científico; inglês para propósitos acadêmicos

ABSTRACT: This paper aims at presenting the analysis of three automatic translators (AT) freely available on the Internet, problematizing the efficiency of these tools as support for understanding scientific texts considering the limitations of this type of translation in relation to various linguistic elements. The study is based on reflections on reading and text comprehension, the concept of translation and the operation of machine translation, as well as the use of automatic translators as a strategy for reading comprehension in English for academic purposes. The results point to differences between the translators that indicate higher reliability/efficiency according to the system employed

\footnotetext{
${ }^{1}$ Mestre e Doutoranda em Letras pela Universidade de Santa Cruz do Sul. Bolsista Capes / Prosuc, com estágio sanduíche na Universidade de Pittsburgh, USA. Email dborsatti@mx2.unisc.br.

2 Doutora em Letras Linguística pela PUCRS (2001), com doutorado-sanduíche no Departamento de Psicologia Experimental da Universidade de Oxford / Inglaterra (1999-2000) e Pós-Doutorado na Université Libre de Bruxelles / Bélgica (2015-2016). Docente Permanente do Programa de Pós-Graduação em Letras da Universidade de Santa Cruz do Sul. Bolsista Produtividade em Pesquisa do CNPq - nível2. Email rgabriel@unisc.br
} 
and highlight the importance of instrumental teaching of reading strategies to ensure comprehension.

KEYWORDS: automatic translator; reading; scientific text; English for academic purposes

\section{Introdução}

A demanda de leitura em línguas estrangeiras não é novidade na educação superior. No entanto, nas últimas décadas, com o fenômeno da globalização e o estreitamento das fronteiras mundiais através da tecnologia e, principalmente, da internet, ler, escrever e publicar pesquisas em línguas adicionais tornou-se fundamental no contexto científico, com ênfase especialmente na língua inglesa (LI). Nesse contexto, a LI pode ser considerada uma língua global ou língua franca, como afirma Jenkins (2007, p.1), "uma língua de contato usada entre povos que não compartilham uma primeira língua, e é comumente entendida como querendo significar uma segunda (ou subsequente) língua de seus falantes". Nas universidades e instituições de pesquisa, a afirmação de Jenkins é particularmente verdadeira, uma vez que as revistas científicas de maior impacto são publicadas em inglês, independentemente da área do conhecimento. Assim, a pesquisa científica, que pressupõe conhecimento atualizado do estado da arte, já há muitos anos elegeu a LI como língua de contato entre os pesquisadores.

A proficiência em línguas estrangeiras é exigida aos alunos de pós-graduação (mestrado e doutorado) a fim de terem acesso às pesquisas internacionais. Essa exigência costuma ser um grande desafio para os estudantes brasileiros devido à falta de conhecimento linguístico. Nos cursos de Inglês Instrumental, comumente ministrados no ambiente universitário, observa-se que os acadêmicos estão habituados a utilizar o tradutor automático (doravante TA, para tradutor automático ou tradução automática) para a realização das leituras em LI, bem como para a produção dos resumos de suas pesquisas. Nesse sentido, a TA é uma ferramenta usada como suporte para a compreensão do texto, considerando que o leitor alia o conhecimento sobre o tema (e sobre a língua materna, tolerando ou parafraseando equívocos dos sistemas automáticos) com a tradução oferecida pela máquina.

Partimos do pressuposto de que a tradução é uma tarefa complexa, tanto para o tradutor humano proficiente, pois implica ir além do conhecimento linguístico, ou seja, 
ultrapassar o significado das palavras isoladamente e manipular categorias e culturas distintas, quanto para a máquina. Ainda assim, é evidente o avanço nos tradutores automáticos ao longo das últimas décadas. Este estudo se propõe a analisar três tradutores automáticos gratuitos disponíveis na internet através da tradução de resumos de pesquisas científicas, textos frequentemente lidos por alunos de pós-graduação.

A problematização parte do questionamento da confiabilidade desse tipo de tradução para leitura e compreensão do usuário, sem o conhecimento consciente de aspectos importantes do âmbito linguístico, como sintaxe, semântica e morfologia e/ou a instrumentalização de estratégias de leitura. Para alavancar essa discussão, propõe-se a análise da tradução de dois resumos de trabalhos científicos através de três tradutores automáticos diferentes. A análise partiu das seguintes questões norteadoras: a TA é suficientemente eficiente para que as lacunas do texto sejam preenchidas pelo leitor? Que tipo de falhas ocorre na tradução automática e como elas podem atrapalhar a compreensão? É possível utilizar a TA como uma ferramenta pedagógica na aula de inglês instrumental?

Iniciaremos a reflexão através da perspectiva de análise do tradutor automático como uma ferramenta de suporte para a compreensão textual.

\section{A leitura e o tradutor como suporte de compreensão}

A compreensão e, em decorrência dessa, a aprendizagem são os grandes objetivos da leitura acadêmica. Para que esses objetivos sejam alcançados, processos cognitivos conscientes e inconscientes são harmoniosamente orquestrados em leitores proficientes. Num nível mais básico, a leitura inicia pelo reconhecimento dos caracteres e pela associação ao que esses representam. No caso dos sistemas alfabéticos, como o português e o inglês, a leitura inicia pelo reconhecimento visual das letras e sua associação aos fonemas que representam, ou pelo reconhecimento das palavras, caso essas já integrem o léxico mental ortográfico do leitor (SOUSA; GABRIEL, 2015). A constituição da memória lexical ortográfica decorre das experiências linguístico-culturais do falante/leitor, e é fundamental para a produção de inferências adequadas à construção de sentido. Assim, em leitores experientes, processos bottom-up e top-down contribuem em diferentes proporções para a compreensão leitora (ZIMMER, 2008). 
Com base no modelo interativo de leitura de Rumelhart (1985), ler é um processo dinâmico de construção de sentido fundamentado na integração do conhecimento prévio do leitor com as formas linguísticas presentes no texto. Por conhecimento prévio do leitor, compreende-se o conhecimento linguístico, o conhecimento textual e o conhecimento de mundo. Conforme Kleiman (2000), é através da interação desses níveis de conhecimento que o leitor constrói o sentido do texto.

Dentre os processos cognitivos que ocorrem no momento da leitura, as inferências possuem um papel essencial. Segundo Marcuschi (1999), inferir é um ato que requer o reconhecimento de proposições dadas que, associadas às novas, permitem ao leitor estabelecer novos sentidos sobre um dado novo.

A importância do conhecimento lexical é destacada por Nuttal (1996, p. 75) ao afirmar que "para inferir o leitor precisa ter pistas suficientes, portanto é importante que haja familiaridade com as palavras". Neste caso, em se tratando de leitura em língua estrangeira, se o leitor não for proficiente, os elementos lexicais serão inconsistentes, gerando um obstáculo para a compreensão, uma vez que ele não conseguirá ativar conhecimento não linguístico para construir o significado.

Por esse viés, o TA pode ser uma ferramenta de grande valia para o leitor com conhecimento linguístico insuficiente da língua alvo, que poderá retirar a ideia principal do texto e a partir disso, acessar o seu conhecimento prévio acerca do assunto para gerar as devidas inferências em direção à construção do sentido. No entanto, o texto traduzido pela máquina nem sempre proporciona uma leitura fluente, sendo um texto "esburacado", conforme qualifica Lima (2008). São muitas as deficiências de ordem estrutural e relacionadas à coesão e coerência textual que podem atrapalhar a fluência na leitura.

O trabalho de Karnal (2015) mostra que o TA, especificamente o Google Tradutor, pode ser um importante aliado na aula de inglês instrumental. Apesar das limitações, em relação à compreensão leitora, a autora cita o estudo com alunos universitários de inglês instrumental, ressaltando que o conhecimento limitado do vocabulário traz dificuldades para a inferência de outras palavras e, consequentemente, para a construção do sentido do texto. A autora explica que:

Partindo-se da ideia de que, para ler e compreender na língua estrangeira, é necessária uma gama de palavras, é que se imagina que o Google Tradutor pode ser de grande ajuda. Para os alunos iniciantes, a tradução do texto todo, ainda que com problemas sintáticos, pode ser entendida pelo menos parcialmente, já que o aluno terá acesso ao core vocabulary, como chama Scaramucci (1997). Para o 
aluno intermediário, a tradução do nível frasal pode facilitar principalmente em relação às questões sintáticas mais complexas, tal como word order, que podem dificultar a compreensão[....] Já para o leitor proficiente, a busca pela palavra dá acesso ao vocabulário procedimental. Nesse sentido, o Google Tradutor pode ajudar os leitores em diferentes níveis de proficiência, principalmente àqueles que desconhecem as palavras. (KARNAL, 2015, p.69)

$\mathrm{O}$ que precisa ser aprofundado nas pesquisas é a investigação que indique até que ponto esses "buracos" podem ser preenchidos somente a partir do conhecimento extralinguístico do aluno e como essas ferramentas podem ser utilizadas de forma pedagógica na aula de inglês instrumental para propósitos acadêmicos.

\section{Um breve histórico da tradução automática}

O desenvolvimento dos primeiros tradutores automáticos ocorreu na década de 40 , juntamente com o avanço da ciência da computação, sendo a primeira aplicação não numérica nessa área, de acordo com Nirenburg (1987). Durante a guerra fria, a TA foi patrocinada pelos governos americano e inglês com o intuito de obter informações da inteligência soviética de forma rápida. O processo era visto na época como algo simples, entretanto, os sistemas desenvolvidos nas décadas de 50 e 60 , com base nas técnicas de linguística computacional e inteligência artificial, conforme descreve Mateus (1995), permaneciam muito abaixo das expectativas e houve um período em que quase todas as pesquisas foram interrompidas pela descrença na TA.

O interesse pela tradução por máquinas retornou nos anos 80 , com o avanço da informatização, juntamente com o desenvolvimento das teorias na linguística formal, como a gramática gerativa de Chomsky e a criação da Comunidade Econômica Europeia. Mais tarde, a revolução digital da década de 90 transformou a forma de comunicação entre as pessoas através de um mundo globalizado e conectado pela rede mundial de computadores. Nesse cenário, a demanda por traduções cresceu e isso impulsionou as pesquisas na área da TA (HUTCHINS, 2006). Nesse momento surgem os primeiros tradutores online gratuitos.

\section{Entendendo o funcionamento dos tradutores automáticos}

Os tradutores automáticos ou machine translators podem ser definidos, de acordo com Hutchins e Somers (1992, p.3), como “(...) sistemas computadorizados responsáveis 
pela produção de traduções de uma língua natural para outra com ou sem a assistência humana”. Segundo Hutchins (2002), na tradução totalmente automática, o sistema traduz todo o texto sem a intervenção do tradutor humano, produzindo uma tradução crua, normalmente conhecida como "tradução informativa" ou "tradução para apreensão de sentido".

A TA pode ser programada para duas línguas (sistemas bilíngues) ou para mais línguas (sistemas multilíngues). Em termos de processamento, os sistemas de TA podem ser agrupados em duas categorias: os sistemas baseados em regras (ruler-based system), em que se enquadram a TA direta, a TA por transferência e a TA por interlíngua), e os sistemas baseados em corpus (TA baseada em estatística e TA baseada em exemplos).

Os sistemas baseados em regras linguísticas apresentam três abordagens principais. A primeira (mais antiga) é através da tradução direta que, como define Hutchins (2003), opera como num grande dicionário bilíngue, no qual o texto de partida é traduzido palavra a palavra, sem haver uma análise aprofundada das suas estruturas sintáticas ou da relação de significados entre as palavras.

A segunda abordagem é a abordagem por transferência, que é mais amplamente utilizada e ocorre em três fases: análise, transferência e geração. Hutchins (2003) explica que os sistemas por transferência podem ter programas separados para a transferência lexical (seleção de palavras equivalentes no vocabulário) e para transferência estrutural (transformação das estruturas da língua de partida em estruturas apropriadas na língua alvo).

A interlíngua é a terceira abordagem que foi desenvolvida na década de 80 e parte do pressuposto de que é possível converter textos da língua de partida (LP) em representações sintático-semânticas comuns em diferentes línguas. A interlíngua está fundamentada nos princípios de uma linguística universal. Assim, a tradução ocorre em duas fases: da língua de partida para a interlíngua e da interlíngua para a língua alvo.

Uma abordagem que está em alta na atualidade é a TA baseada em corpus, que pode ser dividida em duas categorias: a TA baseada em estatística e a TA baseada em exemplos. A TA baseada em estatística não utiliza qualquer tipo de conhecimento linguístico. Somers (2003) esclarece que o modelo baseia-se essencialmente no alinhamento de palavras, expressões e sequências de palavras num corpus bilíngue paralelo e no cálculo das probabilidades de qualquer palavra/expressão numa dada frase de uma 
língua corresponder a uma ou mais palavras da frase equivalente na língua alvo com a qual esteja alinhada.

Para ilustrar, pensemos em um artigo acadêmico, que inicia desta forma:, "O presente artigo..."; este excerto pode ser traduzido por the present article / paper, nesse caso, o TA indicará que, combinada à palavra "artigo", a melhor tradução para "presente" é present e não gift. Diferentemente da frase: "comprei um presente para o aniversário do meu irmão", em que a palavra "aniversário" será associada ao vocábulo gift. Somers (2003) assegura que o cálculo envolvido no processo de tradução adequado em termos de probabilidades estatísticas é enorme, devido à sua grande complexidade.

$\mathrm{Na}$ TA baseada em exemplos, a tradução é feita através da comparação do input com um corpus de exemplos representativos já traduzidos, extraindo as correspondências mais próximas como modelo de tradução para o texto alvo. De acordo com Somers (1998), essa abordagem se assemelha ao modo como os tradutores humanos trabalham, pois busca resolver problemas novos com base em soluções usadas para problemas semelhantes anteriores e, por isso, resulta em traduções mais fluentes e menos literais.

A abordagem estatística é utilizada no Google tradutor, e, portanto, veremos mais adiante que os resultados das traduções são mais confiáveis em relação aos outros dois métodos comparados. Entretanto, conforme problematiza Karnal (2015), apesar dos avanços sistêmicos neste campo, a questão que persiste é porque os textos traduzidos ainda apresentam falhas? Certamente, conforme a autora menciona, a resposta desta questão está ligada ao fato de que a língua é viva, e o contexto de uso é algo extremamente importante para a realização de uma tradução adequada.

\section{Problemas na tradução automática}

Considerando a complexidade envolvida no processo de tradução, poderíamos afirmar que qualquer tradução sem a mínima participação humana não pode acontecer de forma totalmente acurada. Os estudos sobre a tradução através das máquinas são poucos, mas, segundo Hutchins (2003), os erros cometidos pelos tradutores humanos e as máquinas

diferem. É fundamental conceituar o que se entende por tradução em geral e por uma boa tradução a fim de discutir os problemas dos TA, tendo em vista que essa tarefa é executada 
por pessoas muito antes dos computadores e é no funcionamento do cérebro humano que os sistemas estão baseados.

Para Catford (1980, p.22), tradução é "substituição do material textual de uma língua pelo material textual equivalente em outra língua". Apesar de ser parte do processo da tradução, a passagem de certo conteúdo de uma língua para outra implica sempre a mudança de algo a mais, ou seja, essa transformação não se limita apenas aos significantes (SAUSSURE, 2006 [1916]) uma vez que ao compreender a língua como um organismo vivo em constante mudança, o significado se estabelece a partir de um contínuo processo de construção e transformação.

Nesse viés, Arrojo explica que:

Traduzir não pode ser meramente o transporte, ou a transferência, de significados estáveis de uma língua para outra, porque o próprio significado de uma palavra, ou de um texto, na língua de partida, somente poderá ser determinado, provisoriamente, através de uma leitura. (ARROJO, 2000, p.27).

Em outras palavras, o leitor atribuirá o significado a uma sentença através do seu conhecimento, que o levará a uma determinada interpretação, ou seja, há um elemento para além do significado das palavras, que é resultado do processo de leitura e não está contido na explicitude do texto.

A questão da ambiguidade, seja léxica e/ou estrutural, é apontada por Hutchins (2003) como o maior problema dos sistemas de TA. O autor explica que a tradução requer dois tipos de conhecimento: o primeiro é o conhecimento linguístico, que engloba os campos gramatical, semântico e pragmático; e o segundo é o conhecimento extralinguístico, que abarca o conhecimento de mundo e o senso comum. Por ambiguidade lexical, compreendemos os múltiplos conceitos e categorias que podem ser empregados a uma palavra ou expressão, isso porque é comum encontrarmos, em línguas, diferentes palavras que cobrem um mesmo campo semântico, mas que não possuem o mesmo sentido de equivalência, como no exemplo da palavra "presente" (gift/present em inglês), citado anteriormente, ou podemos citar ainda os falsos cognatos, problema bastante recorrente nas traduções.

Desse modo, ao invés de traduzir unidades de código separadamente, é preciso traduzir mensagens completas, conforme conceitua Jakobson (1987, p. 428): "o tradutor recodifica e transmite uma mensagem recebida de outra fonte". 
A não correspondência estrutural ocorre quando as várias línguas utilizam estruturas diferentes para a mesma realidade conceitual ou a mesma estrutura para diferentes realidades conceituais. Por exemplo, o tempo verbal Present perfect, em Inglês, não tem uma correspondência plena ou direta no Português. De acordo com Tucker, é difícil atribuir a uma máquina características humanas realizadas de modo completo e consciente.

Para que a interlíngua represente verdadeiramente o significado conceitual de um texto, ela deve ser capaz de realizar semântica composicional, que, juntamente com regras de semântica inferencial, lhe permitiria fazer deduções lógicas e chegar a uma compreensão mais completa do significado do texto de entrada. (TUCKER, 1987, p.123).

Aqui cabe lembrar o ditado italiano que compara o tradutor a um traidor (traduttore, traditore). De certa forma, é possível endossar essa afirmação pelo viés de que, para traduzir de uma língua para outra, é preciso manter a ideia principal do texto, para que haja uma boa compreensão. Por outro lado, o tradutor precisa fazer concessões e encontrar palavras e expressões mais próximas possíveis do significado original, sabendo de antemão que não há correspondências perfeitas. Um bom tradutor, portanto, precisa saber ler, compreender, interpretar, analisar, decidir e adequar termos, frases e palavras a fim de obter uma tradução mais próxima possível do sentido do texto original. Essa tarefa é bastante complexa para o cérebro humano e um grande desafio para os que desenvolvem os sistemas operacionais.

A seguir, discutiremos a eficiência e os problemas dos tradutores escolhidos para a análise, tendo em vista a problematização da qualidade da tradução em relação ao processo de compreensão leitora e os possíveis conflitos nesse âmbito em virtude das falhas por parte dos sistemas.

\section{Análise}

Dentre os diversos tipos de TA que foram mencionados previamente, o tipo mais simples de tradutor é o baseado em dicionário. Ele opera traduzindo um texto palavra por palavra, pela ordem de aparição. A maior deficiência desse sistema é a inexistência da palavra no contexto e a precariedade da aplicação da lógica gramatical.

A fim de analisar a eficiência e apontar os possíveis problemas encontrados na TA, foram escolhidos dois resumos de pesquisas científicas (abstracts) de áreas diferentes de 
conhecimento, os quais foram traduzidos pelos seguintes tradutores automáticos: Google Tradutor, Wordlingo e Reverso, todos gratuitos e disponíveis na rede.

Dentre os tradutores eletrônicos gratuitos disponíveis na rede, o mais conhecido é o Google Tradutor, sendo acessível aos estudantes em geral e isso levou à decisão de analisar somente tradutores online gratuitos, uma vez que as ferramentas pagas são mais utilizadas por profissionais da tradução.

O primeiro resumo foi escolhido de forma aleatória na rede, em um periódico de sociologia ${ }^{3}$, e foi traduzido da língua inglesa para a língua portuguesa. Com o intuito de verificar o processo inverso, foi escolhido um segundo resumo para ser traduzido da língua portuguesa para a língua inglesa com o intuito de identificar possíveis falhas em ambas as línguas alvo (inglês e português). A versão original em inglês do primeiro resumo, que segue abaixo, foi traduzida pelo Google Tradutor com o seguinte resultado:

Texto 1 - Versão original em inglês

In 2014, the New South Wales government announced that all of the 465 public housing tenants in Millers Point in inner Sydney, are to be relocated and their homes sold. This article, drawing on 41 semi-structured interviews with tenants who were residents at the time of the announcement, has two main aims. First, to contribute to the debate as to the continuity or otherwise of community in a global city in late modernity by closely examining the sense of community among the public housing tenants in Millers Point at the time of the displacement announcement. The second aim is to examine what I have termed 'communicide'. I argue that the displacement policy directed at Millers Point public housing tenants can be described as an act of communicide as it destroyed a vibrant community causing tremendous dislocation and stress. After the move, many tenants found themselves deeply isolated. (MORRIS, 2018)

Texto 2 - Tradução do Google Translator, inglês-português, em maio/2019

Google: Em 2014, o governo de Nova Gales do Sul anunciou que todos os 465 inquilinos de moradias públicas em Millers Point, no interior de Sydney, serão realocados e suas casas vendidas. Este artigo, com base em 41 entrevistas semi-estruturadas com inquilinos residentes na época do anúncio, tem dois objetivos principais. Primeiro, contribuir para o debate sobre a continuidade ou não da comunidade em uma cidade global na modernidade tardia, examinando de perto o senso de comunidade entre os inquilinos de moradias públicas em Millers Point no momento do anúncio do deslocamento. O segundo objetivo é

\footnotetext{
${ }^{3}$ Journal of Sociology - 'Communicide': The destruction of a vibrant public housing community in inner Sydney through a forced displacement. Alan Morris - First Published December 7, 2018 Research Article. Disponível em https://journals.sagepub.com/doi/full/10.1177/1440783318815307.
} 
examinar o que chamei de "communicide". Argumento que a política de deslocamento dirigida aos inquilinos de moradias públicas de Millers Point pode ser descrita como um ato de comunicação, pois destruiu uma comunidade vibrante, causando tremendo deslocamento e estresse. Após a mudança, muitos inquilinos se viram profundamente isolados.

De modo geral, ao ler o resumo traduzido pela ferramenta, é possível compreendê-lo, pois há coerência e coesão textual. No entanto, percebem-se equívocos, como em "modernidade tardia", quando a palavra "late", neste contexto, significa "recente", porém esse adjetivo/advérbio é mais comumente utilizado no sentido de "tarde, tardio, atrasado", portanto, em um sistema estatístico, esse seria mais provável. Os problemas de tradução forma grifados, tanto nesta quanto nas demais traduções que seguem.

O conceito communicide, apresentado pelo autor, une as palavras community (comunidade) e homicide (homicídio). Portanto, a tradução deveria ser comunicídio. Contudo, a ferramenta automática ainda não é capaz de atingir a flexibilidade que é possível ao cérebro humano. Talvez fosse necessário abastecer o sistema com informações referentes à morfologia afim de sanar este tipo de deficiência. Na segunda vez em que a palavra comunicide aparece no texto ela é traduzida simplesmente como comunicação, e isso compromete ainda mais a compreensão do texto pelo leitor da tradução.

Resta saber se o leitor saberia interpretar esse tipo de situação lexical e percorrer o raciocínio morfológico necessário para poder compreender o texto, uma vez que este parece ser um conceito essencial do texto. É muito provável que, se o leitor tiver um conhecimento superficial da língua inglesa, ele não consiga compreender, considerando que aspectos morfológicos como afixos não são facilmente inferidos sem uma aprendizagem explícita e consciente. Nessa direção, em uma aula de inglês instrumental, o texto poderia ser utilizado como instrumento pedagógico para demonstrar os aspectos morfológicos da língua alvo. A tradução da segunda ferramenta foi a seguinte:

Texto 3 - Tradução do Wordlingo, inglês-português, em maio de 2019

WORDLINGO: Em 2014, o governo de (1)Novo Gales do Sul anunciou que todos os 465 tenants da carcaça pública nos moleiros apontam em Sydney interno, deve relocated e seus repousos ser vendido. Este artigo, extraindo em 41 entrevistas semi-estruturadas com tenants que eram residentes na altura do anúncio, tem dois alvos principais. 
Primeiramente, para contribuir ao debate a respeito da continuidade ou de outra maneira da comunidade em uma cidade global na modernidade atrasada pròxima examinando o sentido da comunidade entre os tenants da carcaça pública nos moleiros aponte na altura do anúncio do deslocamento. O segundo alvo é examinar o que eu denominei communicide do ". Eu discuto que a política do deslocamento dirigida em tenants da carcaça pública do ponto dos moleiros pode ser descrita como um ato do communicide enquanto destruiu uma comunidade vibrant que causa o dislocation e o stress tremendos. Depois que o movimento, muitos tenants se encontrou isolados profundamente.

É importante notar que esta tradução apresenta um número bem superior de palavras e expressões grifadas em relação à tradução do Google e isso se deve ao fato deste tradutor operar como um dicionário, realizando a tradução direta, palavra por palavra, enquanto que o Google utiliza a metodologia de tradução estatística.

Algumas palavras permanecem em inglês, como tenants, vibrant, dislocations, stress. Além disso, a palavra housing foi traduzida como "carcaça", que pode ser um dos significados; entretanto, neste contexto, não é apropriada, gerando uma falta de equivalência semântica. Miller Point, o bairro onde o fato ocorreu, é traduzido como "moleiros apontam", e neste caso, a coerência do texto é prejudicada e a frase perde completamente o sentido.

"Sydney interno" para Inner Sydney comprova a tradução por palavras e não pela estatística. Ao final do Texto 3, "move" aparece como "movimento", porém o real sentido é a mudança das residências das pessoas para outro local. Temos aqui uma ambiguidade semântica que é mais facilmente identificada por um tradutor humano, que associará "move" ao contexto de mudança de residência, de endereço, uma vez que as palavras housing, homes, residents, displacement remetem a esse frame semântico (FILLMORE, 2009). Entretanto, se compararmos o Texto 1 à tradução do Google, veremos que, no Texto 2, a tradução está adequada, demonstrando a superioridade do método estatístico.

Há também o aspecto sintático estrutural, como no trecho final "muitos tenants se encontrou isolados profundamente", em que, além do termo não traduzido, há aparentes problemas de concordância verbal (muitos tenants se encontrou) e também de ordem sintática, uma vez que o advérbio "profundamente" deveria vir antes de "isolados" na sequência da frase em português. Isso demonstra que a estrutura da língua alvo não é 
levada em conta neste tipo de tradução, que utiliza uma metodologia primária, ou seja, funciona como um dicionário e torna incoerente o texto, prejudicando a sua compreensão.

O Texto 4 traz a tradução do Texto 1 por meio do aplicativo Reverso.

Texto 4 - Tradução Reverso, inglês-português, em maio 2019

REVERSO: Em 2014, anunciou o governo de New Sul Gales que todos os 465 inquilinos de alojamento públicos em Miller Point em Sydney interno, será Localizado de novo e as casas deles/delas venderam. Este artigo, enquanto utilizando 41 entrevistas semi-estruturadas com inquilinos que eram os residentes na hora do anúncio, tem duas pontarias principais. Primeiro, contribuir ao debate sobre a continuidade ou caso contrário de comunidade em uma cidade global em recente modernidade examinando o senso de comunidade de perto entre o alojamento público habita em Miller Point na hora do anúncio de deslocamento. A segunda pontaria é examinar o que eu tenho termed 'communicide.' Eu discuto que a política de deslocamento dirigiu a Miller Point que podem ser descritos os inquilinos de alojamento públicos como um ato de communicide como destruiu uma comunidade vibrante que causa tremenda deslocação e tensão. Depois do movimento, muitos inquilinos se acharam profundamente isolado.

É evidente que o Reverso opera de forma bastante semelhante ao Wordlingo, e, portanto, as falhas nesta tradução se aproximam daquelas apontadas no texto anterior, contendo alguns elementos distintos, como, por exemplo, na frase inicial: "anunciou o governo...", esta é uma ordem sintática que pode até ser compreendida pelo leitor, porém não utilizada na língua portuguesa. Além disso, o nome do Estado é traduzido de modo incompleto New Sul Gales e, assim como na tradução do Wordlingo, Sydney interno é a tradução para Inner Sydney, que seria no interior de Sydney.

Problemas de ordem de concordância verbal também podem ser observados, como nas conjugações de "venderam", "será localizado", "dirigiu”, “causa", que estão grifadas no texto. Outro aspecto a ser destacado é a inclusão dos pronomes "dele/dela" para o pronome their, mostrando a não correspondência na língua alvo dessa retomada anafórica. A referência acontece em relação aos moradores do local de modo geral, portanto poderia ser simplesmente "suas casas serão vendidas".

Muitos vocábulos foram traduzidos literalmente como "enquanto". Há também falha de ambiguidade semântica em "pontaria" para "aim", o uso da palavra "deslocação" ao invés de "deslocamento", "localizado de novo" ao invés de "realocado", "movimento" ao invés de "mudança”. Além disso, assim como na tradução anterior, algumas palavras 
como termed, communicide não foram traduzidas. Entretanto, o aspecto que mais pode prejudicar a compreensão leitora está relacionado à estrutura geral de algumas frases que estão incoerentes, como, por exemplo, “examinado o senso de comunidade de perto entre o alojamento público habita em..." A falta de concordância de número também está presente no final do Texto 4, na frase que indica que os moradores ficaram profundamente "isolado".

A segunda etapa de nossa investigação explora a TA de um resumo escrito em português e traduzido para inglês. O artigo foi retirado da revista Signo ${ }^{4}$, periódico científico da área de Linguística e Literatura.

\section{Texto 5 - Versão original em português}

O presente artigo discute as atribuições dos professores de linguística e de língua portuguesa de acordo com seu contexto de atuação profissional (professores pesquisadores, professores universitários e professores de escola) e sua responsabilidade quanto ao ensino de língua materna na educação básica. Ao mesmo tempo, reconhece a falta de intercâmbio entre universidade-escola e de efetividade do ensino de língua nas escolas públicas brasileiras, levantando algumas hipóteses sobre o motivo causador do atual estado de coisas. Para finalizar, sugere que, no seu espaço de atuação regional, as universidades passem a se preocupar com pesquisa em ensino, ocupando-se ainda com o acompanhamento e a orientação aos professores das escolas, no que respeita ao ensino de língua, no ensino fundamental e médio. (FLORES, 2017)

Texto 6 - Tradução do Google Translator, português-inglês, em maio/2019

Google: This article discusses the responsibilities of linguistics and Portuguese language teachers according to their professional context (research professors, university professors and school teachers) and their responsibility for the teaching of mother tongue in basic education. At the same time, it recognizes the lack of interchange between university-school and effectiveness of the teaching of language in the Brazilian public schools, raising some hypotheses on the reason that causes the current state of things. To conclude, it suggests that, in their regional area of activity, universities should become concerned with research in teaching, and be involved in the monitoring and guidance to teachers of schools, in terms of language teaching, in elementary education is medium.

\footnotetext{
${ }^{4}$ Disponível em https://online.unisc.br/seer/index.php/signo/index; acesso em 2/maio/2019.
} 
Observa-se que o texto é passível de compreensão e apresenta poucos pontos a serem analisados como falhas do TA. Um deles é a expressão "at the same time", traduzida de modo literal, porém a conjunção mais comumente utilizada em língua inglesa para expressar concomitância é likewise. Além disso, "the teaching of the language" também está literal e traduzido diretamente, ou seja, não está de acordo como a estrutura da língua inglesa que seria language teaching. Nesse caso, foram acrescentados artigos e preposições desnecessariamente.

O tradutor não reconheceu o termo usado para classificação escolar no Brasil, "Ensino Médio", que corresponde a High School nos Estados Unidos. Entretanto, se a tradução for isolada no Google, ou seja, se buscarmos "Ensino Médio" em português, a resposta da ferramenta é High School. Nesse sentido, a tradução estatística falhou. As traduções do Wordlingo e do Reverso seguem abaixo, evidenciando mais uma vez a diferença destes sistemas em comparação ao Google Tradutor.

Texto 7 - Tradução do Wordlingo, português-inglês, em maio/2019

Worlingo: The present article in accordance with argues the attributions of the professors of linguistics and Portuguese language its context of professional performance searching professors, university professors and professors of school and its responsibility how much to the language education materna in the basic education. At the same time, it recognizes the lack of interchange between university-school and effectiveness of the education of language in the Brazilian public schools, raising some hypotheses on the .causing reason of the current state of things. To finish, it suggests that, in its space of regional performance, the universities pass if to still worry about research in education, occupying with the accompaniment and the orientation to the professors of the schools, in what it respects to the language education, in basic and average education.

Assim como na tradução inglês-português, o número de palavras e expressões grifadas é bem superior na versão Wordlingo em relação ao resumo do Google. Dentre as deficiências apontadas nesse texto, destaca-se principalmente o fato de ser uma tradução extremamente direta, o que resulta em falta de coerência textual devido à alteração da ordem das palavras e frases.

Há também equívocos referentes ao uso de preposições como é o caso de of the professor of linguistics - que poderia ser of linguistics professor. Searching professors está erroneamente traduzido, quando o correto seria researchers e também a palavra professor 
foi usada tanto para professores de nível básico (que seriam teachers) como para nível universitário, uma distinção que ocorre em LI e não em língua portuguesa.

Outros pontos a serem destacados são: a palavra "materna" não foi traduzida; expressões foram traduzidas de modo literal como at the same time e to finish. Somando-se a isso, as classificações escolares, ensino fundamental e médio não obtiveram os termos corretos, permanecendo "basic and average education", bastante literais. É importante reiterar que a forma de tradução, ou seja, o sistema direto, palavra por palavra, é o que torna a tradução literal, a ponto de se perder a coerência e, consequentemente, o sentido, o que dificulta a compreensão. Vejamos o resultado da tradução pelo aplicativo Reverso.

Texto 8 - Tradução Reverso, português-inglês, em maio/2019

REVERSO:The present article discusses the linguistics teachers' attributions and of Portuguese language in agreement with his/her context of professional searching teachers, academical teachers and school teachers performance and his/her responsibility as for the teaching of maternal language in the basic education. At the same time, it recognizes the exchange lack among university-school and of effectiveness of the language teaching in the Brazilian public schools, lifting some hypotheses on the reason cause of the current state of things. To conclude, he/she suggests that, in his/her space of regional performance, the universities pass worrying with research in teaching, being still in charge of with the attendance and the orientation to the teachers of the schools, in what respects to the language teaching, in the fundamental teaching and medium teaching.

O Texto 8 evidencia a semelhança entre o modo de operar dos tradutores Wordlingo e do Reverso, bem como demarca a diferença desses dois em relação ao Google. Embora muito semelhante à tradução anterior, este resumo apresenta outros tipos de falhas. Observa-se problemas relacionados a pronomes, como his/her na retomada anafóricas para teachers, que deveria ser their. Ao contrário da tradução anterior, que utilizou professor para todos os professores, aqui teacher aparece como a única escolha lexical. O único tradutor que distinguiu ambos os termos foi o Google. A expressão "maternal language" ao invés de "mother language" é traduzida de modo literal. Observa-se, ainda, erros de ordem sintática como "exchange lack", para falta de intercâmbio (lack of exchange), além de outras expressões que, traduzidas de modo literal, direto, perdem o sentido em língua inglesa. 


\section{Considerações finais}

Este estudo demonstra que os sistemas dos tradutores automáticos têm sido aperfeiçoados ao longo das últimas décadas e que novas metodologias estão sendo empregadas com bases linguísticas e interdisciplinares. Há uma evidente diferença entre o Google Tradutor em relação ao Wordlingo e o Reverso, sendo o primeiro mais confiável no corpus analisado, tendo em vista que apresenta menos incoerências e falhas do que os demais. Portanto, o texto traduzido pelo Google pode ser considerado mais compreensível do que os outros dois e isso se explica devido ao sistema estatístico aliado ao fato dessa ferramenta utilizar um imenso banco de dados, apresentando uma tradução mais clara e coerente, ainda que imperfeita.

As ferramentas disponíveis podem auxiliar os estudantes na compreensão de textos. É necessário, entretanto, estudá-las, a fim de orientar os alunos sobre suas fragilidades e seus méritos. Além disso, saber diferenciar sistemas e entender suas falhas é importante para os professores de línguas estrangeiras, visto que este conhecimento poderá guiar os aspectos a serem trabalhados nas aulas de inglês instrumental, por exemplo, usando a ferramenta como instrumento pedagógico de modo eficaz e/ou até mesmo auxiliar nas investigações no sentido de contribuir para o aperfeiçoamento dos sistemas disponíveis.

Vale ressaltar que estamos tratando de uma tradução de um resumo de estudo científico, um tipo de texto que geralmente apresenta uma linguagem denotativa, ou seja, mais direta, tendo em vista que contém dados objetivos relacionados aos estudos desenvolvidos. O resultado poderia ser bastante diferente no caso de textos literários, especialmente os poéticos, em que as figuras de linguagem estão presentes, o que, sem dúvida, torna a tradução muito mais complexa.

Por fim, é importante frisar que estudos mais aprofundados precisam ser conduzidos, principalmente no sentido de buscar desenvolver metodologias que possam quantificar os graus de compreensão de um texto traduzido automaticamente e os aspectos cognitivos envolvidos neste processo, além de investigar a validade do uso do Google Tradutor como instrumento pedagógico.

\section{REFERÊNCIAS}


ARROJO, Rosemary. Oficina de tradução; a teoria na prática, Editora Ática, São Paulo, 2000.

BASSNETT, Susan. Estudos de tradução. Porto Alegre: Editora da UFRGS, 2003.

CATFORD, John. C. Uma teoria lingüística da tradução, Cultrix, São Paulo, 1980.

FILLMORE, C. J. Semântica de Frames. Cadernos de Tradução UFRGS, n. 25, jul-dez, 2009.

FLORES, Onici. C. Ensino de língua, o calcanhar de Aquiles da linguística. Signo. Santa Cruz do Sul, v.42, n. 75, p. 89-103, set./dez. 2017.

Goodman (1984)

HUTCHINS, John. and Somers, Harold L. (1992) An introduction to Machine Translation, Academic Press, San Diego (CA).

HUTCHINS,John. Machine Translation: History. Encyclopedia of Language \& Linguistics. Elsevier, 2006.

HUTCHINS, John. Commercial Systems: The state of the art. In: SOMERS, Harold. L. (Ed.) Computers and translation: a translator's guide. Amsterdam: John Benjamins Publishing Company, 2002. p.367.

HUTCHINS, John. Machine Translation. In: MITKOV, Ruslan. The Oxford handbook of computational linguistics. Oxford: Oxford University Press, 2003.

JAKOBSON Roman. On Linguistic Aspects of Translation, in Language in Literature, edição de Krystyna Pomorska e Stephen Rudy, Cambridge (Massachusetts), Harvard University Press, 1987, p. 428-435. ISBN 0-674-51028-3.

JENKINS, Jennifer. English as a Lingua Franca: Attitude and Identity. Oxford: OUP, 2007.

KARNAL, A. R. As estratégias de leitura sem e com o uso do Google Tradutor. Tese de doutorado em Letras. Faculdade de Letras. Pontifícia Universidade Católica do Rio Grande do Sul - PUCRS, 2015.

KLEIMAN, Angela. Oficina de leitura: teoria e prática. 7. ed. Campinas: Pontes, 2000.

LEFFA, Vilson. J. Aspectos da leitura: uma perspectiva linguística. Porto Alegre: Sagra:

DC Luzzatto, 1996.

LIMA, Luciano. Tradução eletrônica: do riso irônico ao interesse científico. Fólio Revista de Letras, 2011.

MARCUSCHI, Luiz Antônio. .(1999) Leitura como processo inferencial num universo cultural-cognitivo. In: BARZOTTO, Valdir Heitor (Org.). Estado de Leitura. Campinas, SP: Mercado de Letras.

MATEUS, Maria Helena. "Tradução automática: um pouco de história”. Engenharia da Linguagem. Org. Maria Helena M. Mateus e António Horta Branco. Lisboa, Edições Colibri, 1995, pp. 115-120.

MORRIS, Alan. 'Communicide': The destruction of a vibrant public housing community in inner Sydney through a forced displacement.First Published December 7, 2018. 'Communicide': The destruction of a vibrant public housing community in inner Sydney through a forced displacement" First Published December 7, 2018. Disponível em: https://journals.sagepub.com/doi/full/10.1177/1440783318815307. Acesso em 05/01/19.

NIRENBURG,Sergei. (Ed). (1987). Machine Translation - Theoretical and Methodological Issues, Cambridge University Press, Cambridge.

NUTTALL, Christine. Teaching reading skills in a foreign language. Oxford: Heinemann English Language Teaching, 1996.

RUMELHART, David. Toward an interactive model of reading. In: SINGER, H; RUDDELL, Robert. Theoretical models and process of reading. 3ed. Newark, International Reading Association, 1985, p. 722-751. 
SAUSSURE, Ferdinand de. Curso de linguística geral. Trad. de A. Chelini; J. P. Paes e I. Blikstein. 27 $7^{\text {a }}$ Ed. São Paulo: Cultrix, 2006. Cours de linguistique general. Charles Bally e Albert Sechehaye (orgs.), com a colaboração de Albert Riedlinger, [1916].

SCARAMUCCI, Matilde. A competência lexical de alunos universitários aprendendo a ler em inglês como língua estrangeira. DELTA. Documentação de Estudos em Lingüística Teórica e Aplicada [on-line], v. 13, n. 2, p. 215-246, 1997.

SOMERS, Harold. Machine translation. In Baker, M. (Ed.) Routledge encyclopedia of translation studies. Londres: Routledge. p.136-139. 1998.

SOMERS, Harold. Machine translation: latest developments. In: MITKOV, R. The Oxford handbook of computational linguistics. Oxford: Oxford University Press, 2003.Somers, 2003.

SOUSA, Lucilene Bender de; GABRIEL, Rosangela. Does the mental lexicon exist?. REVISTA DE ESTUDOS DA LINGUAGEM, [S.1.], v. 23, n. 2, p. 335-361, sep. 2015. ISSN 2237-2083. Available

at: $<$ http://periodicos.letras.ufmg.br/index.php/relin/article/view/5642>. Date accessed: 03 july 2019. doi:http://dx.doi.org/10.17851/2237-2083.23.2.335-361.

TUCKER, Alien. B. "Current Strategies in Machine Translation Research and Development".Machine Translation. Org. Sergei Nirenburg. Cambridge, Cambridge University Press, 1987, pp. 22-41.

ZIMMER, Márcia Cristina. O processamento da leitura em língua materna e em língua estrangeira: uma abordagem conexionista. Signo, Santa Cruz do Sul, ago. 2008. ISSN 1982-2014. Disponível em:

$<$ https://online.unisc.br/seer/index.php/signo/article/view/439/292>. Acesso em: 03 jul. 2019. doi:https://doi.org/10.17058/signo.v31i0.439. 